\title{
Voltage Distribution of Internal Windings of Pole-Mounted Distribution Transformer by Lightning Surge and Measures for Voltage Reduction
}

\author{
Hideki Honda* Member \\ Akira Asakawa* Member \\ Shigeru Yokoyama** Member
}

\begin{abstract}
When steep lightning surge enters a pole-mounted distribution transformer, the voltage distribution of the internal windings is unbalanced. It is known that a layer-to-layer short or a turn-to-turn short occurs where the voltage distribution of windings is high. In this paper, the voltage distribution of the windings was measured at the primary and secondary sides of the transformer using a testing transformer. The point of the windings where the highest voltage occurred was clarified. At the primary windings, large voltage occurs at the layer nearest the primary bushing, and the possibility of breakdown at this point is high. By field test using several types of surge arrestor, it is found that the lower the operating voltage of the surge arrestor installed in the primary side, the lower the voltage occurring at the primary windings. At the secondary windings, large voltage occurs at the layer closer to the neutral terminal, and the possibility of breakdown at this point is high. The lower the operating voltage of the surge arrestor installed in the primary side, the lower the voltage occurring at the secondary windings, too. Adding the surge arrestor in the secondary side, although effectively reduce line-to-line voltage, does not effectively reduce the voltage of the secondary windings.
\end{abstract}

Keywords: lightning, distribution line, pole-mounted transformer, lightning protection design, layer short

\section{Introduction}

For years, the ratio of outage caused by lightning damage of pole-mounted transformers has been the highest of all equipment used in distribution lines ${ }^{(1)}$. As our information society advances, the needs for supply reliability become higher, and the decrease in the number of lightning breakages of pole-mounted transformers becomes necessary. In recent years, lightning protective devices (surge arrestors) with some built-in $\mathrm{ZnO}$ elements have been installed around the primary bushing of transformers. Therefore, the number of disconnections around the primary bushing caused by lightning has been decreasing. On the other hand, the internal breakages of the transformers have been occurring. It is known that the voltage distribution of the windings is unbalanced when steep overvoltage enters the pole-mounted distribution transformer ${ }^{(2)(3)}$ and that a layer-to-layer short or a turn-to-turn short occurs where the voltage distribution of windings is high. The steepness of overvoltage is influenced by the operating voltage of the surge arrestor. However, concrete measures have not been investigated to date. The establishment of effective measures has been hoped for. In this paper, the voltage distributions of the primary and the secondary windings are measured using a testing transformer. Then, the weak point of the windings where the highest voltage occurs is specified. Aiming at the reduction of voltage in the windings, the effects of the difference in the operating voltage and arrangement of the surge arrestor and the

\footnotetext{
* Research \& Development Center Tohoku Electric Power Co., Inc.

7-2-1, Nakayama, Aoba-ku, Sendai 981-0952

** Electric Power Engineering Research Lab. CRIEPI

2-6-1, Nagasaka, Yokosuka 240-0196
}

decrease in grounding resistance are examined.

\section{Field-test Setup}

2.1 Structure of Testing Transformer The structure of the testing transformer is shown in Fig. 1. The twelve layers of the primary windings are wound outside of the two layers of the secondary windings on one side of the core.

The structure of the primary windings is as follows. There are 24 layers of primary windings. The layers, which are nearest to the tap board, consist of 66 turns (tap $6600 \mathrm{~V} / 105 \mathrm{~V}$ ), and the other layers consist of 234 turns. To measure the voltage between the adjacent layers of the primary windings, the measurement terminals are drawn out as shown in Fig. 1(b). The terminals drawn out enable the measurement of the voltages $\mathrm{V}_{\mathrm{h}} 1-\mathrm{V}_{\mathrm{h}} 12$ (from 1 terminal to $1^{\prime}$ terminal).

The structure of the secondary windings is as follows. There are four layers of secondary windings. Each layer consists of 21 turns. Two measurement terminals are drawn out from the inside of secondary windings, and they enable the measurement of the voltages $\mathrm{V}_{1} 1-\mathrm{V}_{1} 4$ and the voltage $\mathrm{V}_{1} \mathrm{t}$.

2.2 Experimental Distribution Line Figure 2 shows the experimental distribution line. This distribution line consists of eleven poles, a high-voltage distribution line, and a low-voltage distribution line. The high-voltage distribution line (Pole No.1 to Pole No.11) is a 3-phase 3-wire system, and the conductors are $430 \mathrm{~m}$ long. All conductors are connected to terminal resistances $(380 \Omega)$ to prevent the reflection of traveling waves, and they are grounded together at Pole No.1 (119 $\Omega$ ) and Pole No.11 (116 $\Omega$ ). The lowvoltage distribution line (Pole No.6 to Pole No.10) is a 1phase 3-wire system, and the conductors are $164 \mathrm{~m}$ long; all 


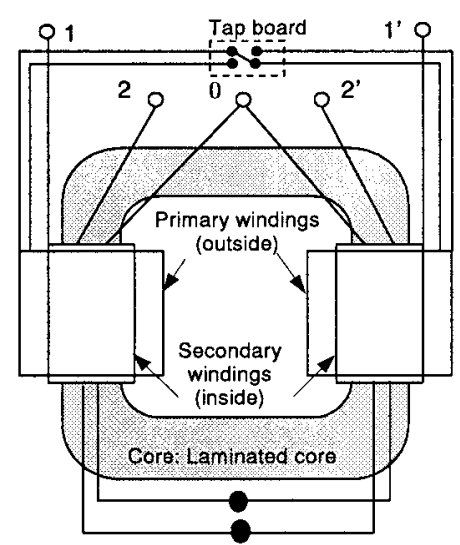

(a) Outline

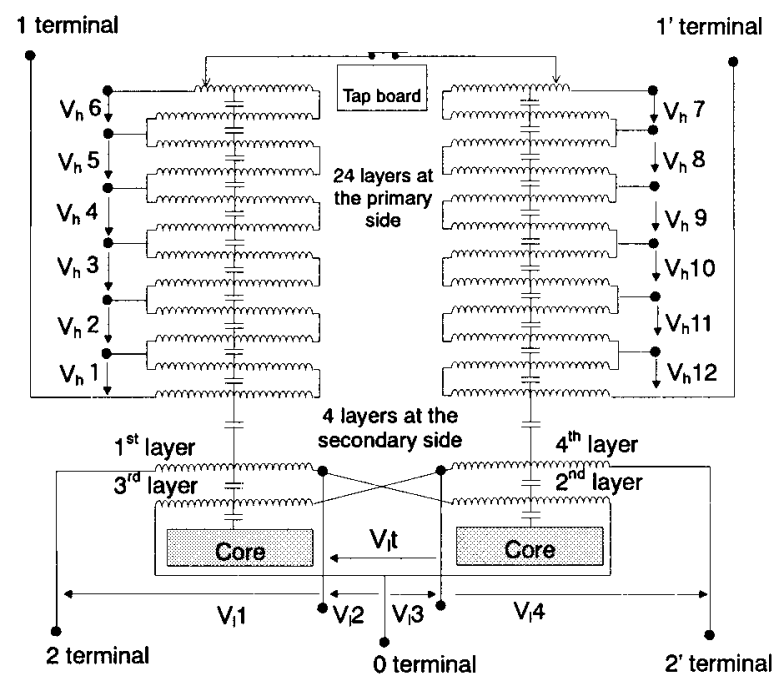

(b) Arrangement of layers of windings

Fig. 1. Internal structure of testing transformer

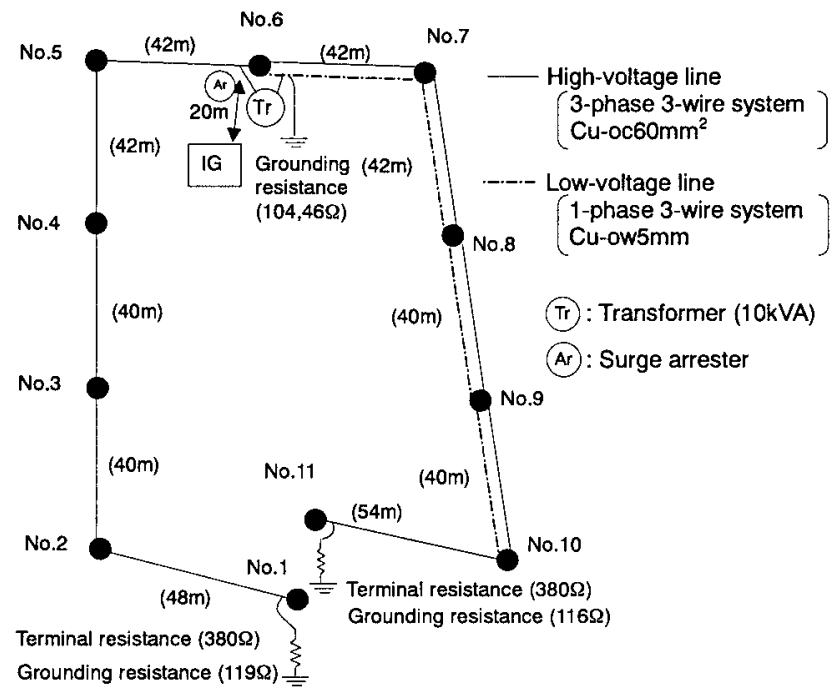

Fig. 2. Schematic diagram of experimental distribution line used in field tests

conductors are open-ended. The capacity of the transformer (testing transformer) on Pole No.6 is $10 \mathrm{kVA}$. Figure 3 shows the connection of the high-voltage and low-voltage wires in the transformer. The measuring points for voltage and current are shown in Fig. 3.

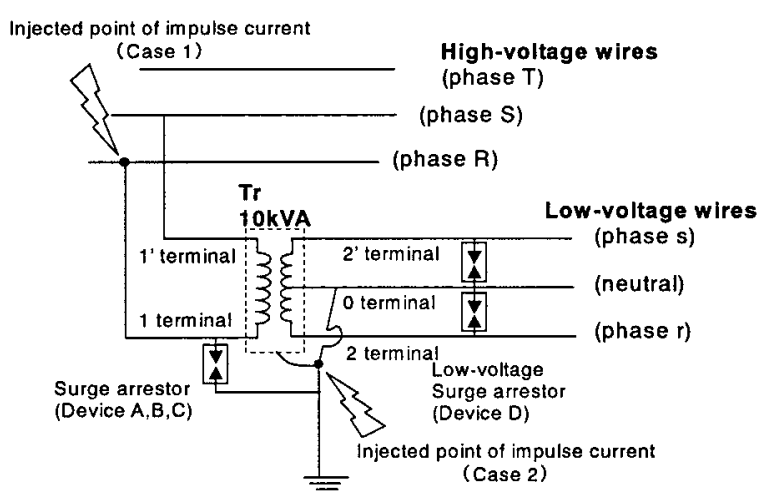

Fig. 3. Circuit around transformer and injected point of impulse current

Table 1. Specifications of the surge arrestors used in field tests

\begin{tabular}{|c|c|c|c|}
\hline name & $\begin{array}{c}\text { Internal } \\
\text { Gap }\end{array}$ & $\begin{array}{c}\text { Operating voltage } \\
(8 / 20 \mu \mathrm{s})\end{array}$ & $\begin{array}{c}\text { Clamping Voltage } \\
\text { at } 2500 \mathrm{~A} \\
(8 / 20 \mu \mathrm{s})\end{array}$ \\
\hline Device A & exists & under $55 \mathrm{kV}$ & under $20 \mathrm{kV}$ \\
\hline Device B & exists & under $33 \mathrm{kV}$ & under $33 \mathrm{kV}$ \\
\hline Device C & none & under $15 \mathrm{kV}(1 \mathrm{~mA})$ & under $33 \mathrm{kV}$ \\
\hline Device D & none & under $250 \mathrm{~V}(1 \mathrm{~mA})$ & under $620 \mathrm{~V}$ \\
\hline
\end{tabular}

2.3 Injected Point of Lightning Impulse Current

To examine the influence of the injected point of impulse current on the voltage distribution of windings, examinations are carried out for two cases. Case 1: impulse current is injected into one phase (phase R) of high-voltage wires at pole No.6. In this case, a direct lightning hit to the high-voltage wire is assumed. Case 2: impulse current is injected into the pole head. In this case, a direct lightning hit to the pole head is assumed. In Case 2, on the assumption that the current injected at the pole head flows into the iron framework of concrete and sparks to the enclosure of the transformer, the route of injected current is the same as in the case of current being injected in a low-voltage neutral wire. Figure 3 shows the circuit around the transformer and the injected points of the impulse current for each case.

2.4 Arrangement of Surge Arrestors Aiming to reduce the voltage occurring in internal windings, field tests using various surge arrestors installed around the transformer were carried out. Figure 3 shows the arrangements of the surge arrestors. The list of the specifications of the surge arrestors is shown in Table 1. Devices A, B, and C had some $\mathrm{ZnO}$ elements built in (Device A: one element, Device B: two elements in series, Device C: three elements in series). The characteristics of these $\mathrm{ZnO}$ elements are the same. The influence of the difference in the operating voltage of the surge arrestors (Devices A, B and C) on the reduction in the voltage of the internal windings was examined. Incidentally, the surge arrestors, which are specified as having the same operating voltage, work at slightly different voltages when they are installed in both $\mathrm{R}$ and $\mathrm{S}$ phases. Therefore, to eliminate the influence of the difference in operating voltage, all field tests using the surge arrestors are carried out with the surge arrestor installed in the phase R. With Device A installed in the primary side, the influence of Device D (low-voltage 


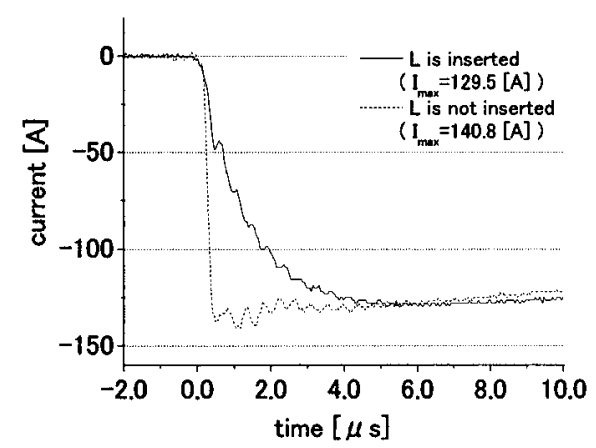

Fig. 4. Difference in waveforms of injected current for cases with and without $\mathrm{L}$

arrestors) installed in the secondary side on the reduction in the voltage of the secondary windings was examined, too.

2.5 Waveform of Injected Current To examine the influence of the wavefront time of the applied voltage on the voltage distribution of windings, the case with a slow wavefront (1.2 $\mathrm{mH}$ inductance is inserted in the lead wire) and the case with a steep wavefront (no inductance is inserted) are investigated. To prevent the reflection of traveling waves, $400 \Omega$ resistances are connected to both sides of the lead wire connecting the $600 \mathrm{kV}$ IG and the lightning current injection point (Pole No.6). Figure 4 shows the difference in the waveform of the injected current for the cases with and without the inductance $(1.2 \mathrm{mH})$.

\section{Voltage Distribution of Primary Windings}

\subsection{Influence of Wavefront Time of Injected Current}

It is difficult to understand the transfer between the primary and secondary sides when breakdown occurs around the transformer. Therefore, a current with a peak value less than $150 \mathrm{~A}$ is injected to avoid breakdown.

(1) Case1 (impulse current is injected into high-voltage wire) The voltage distribution of the primary windings caused by the transfer from the primary side to the secondary side is measured. The distribution of voltage peak value measured between the adjacent layers is shown in Fig. 5. It is confirmed that the highest voltage occurs at $V_{h} 1$ that is nearest to the injected point. The distribution of $\mathrm{V}_{\mathrm{h}} 1-\mathrm{V}_{\mathrm{h}} 6$ (the side of terminal 1) is more influenced by the steepness of injected current than the distribution of $\mathrm{V}_{\mathrm{h}} 7-\mathrm{V}_{\mathrm{h}} 12$ (the side of terminal $\left.1^{\prime}\right)$. The reason for this is that the transfer by electrostatic induction is more effective at the side of terminal 1 . When the slow wavefront current is injected, the voltage distribution is almost flat. The reason the voltages of $\mathrm{V}_{\mathrm{h}} 6$ and $\mathrm{V}_{\mathrm{h}} 7$ are lower than the others is that the number of turns constituting the layers nearest to the tap board (66 times) is less than the number of turns constituting other layers (234 times).

(2) Case2 (impulse current is injected into the pole head)

In Case2, the voltage distribution caused by the transfer from the secondary side to the primary side is measured. Figure 6 shows the voltage distribution of the primary windings in Case2. It is found that a higher voltage occurs at the windings nearer both primary bushings. Compared with Case1, the voltage distribution is much lower, although the peak value of the injected current is almost the same. The reason for this is that most of the injected current flows into the earth before it flows into the transformer. The voltage

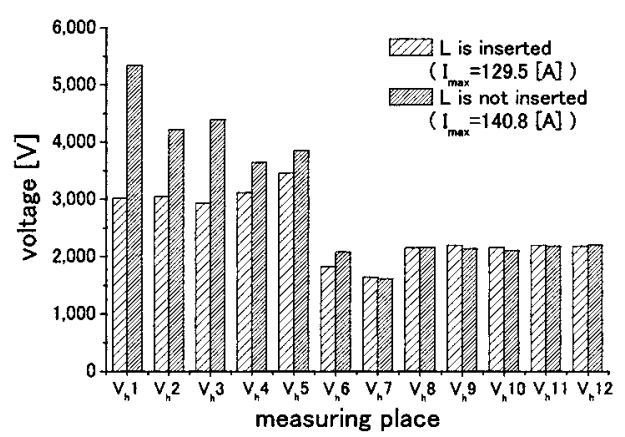

Fig. 5. Voltage distribution of primary windings (Case 1, no surge arrestor, grounding resistance $46 \Omega$ )

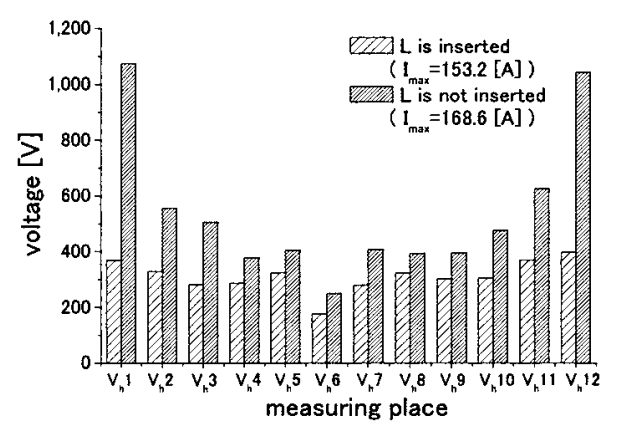

Fig. 6. Voltage distribution of primary windings (Case2, no surge arrestor, grounding resistance $46 \Omega$ )

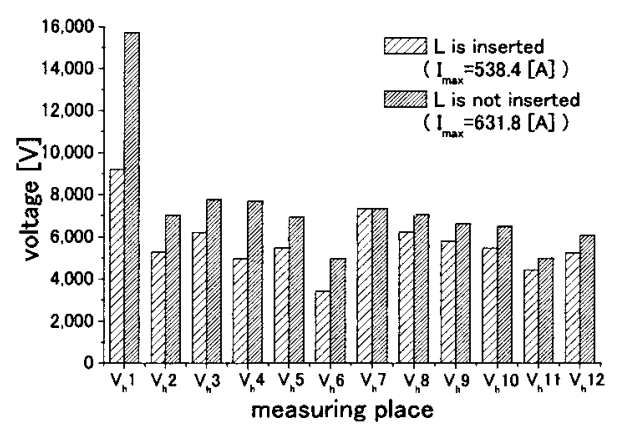

Fig. 7. Voltage distribution of primary windings (Case1, Device A, grounding resistance $104 \Omega$ )

distribution is balanced symmetrically. The reason for this is that the current flows into the 0 terminal of the secondary side and the structure of the transformer is symmetrical.

3.2 Influence of the Surge Arrestor Operation The surge arrestors are usually installed around the transformers in actual distribution lines. Therefore, understanding the influence of the surge arrestor operation upon the voltage distribution of windings is important. In this case, the field test is carried out using Device A that has been adopted by a certain electric power company.

(1) Case1 Figure 7 shows the voltage distribution of the primary windings in Case 1 . When Device A operates, the operating current of Device A flows into the 0 terminal of the transformer. However, most of the operating current flows into the earth, and a little of it flows into the transformer. Therefore, the voltage, which is transferred from the secondary side to the primary side, is small. In this case, the voltage distribution is dominated by the trend observed in Case 1 of former section 3.1. Figure 8 shows the difference in waveforms of bushing voltage for cases with and without 


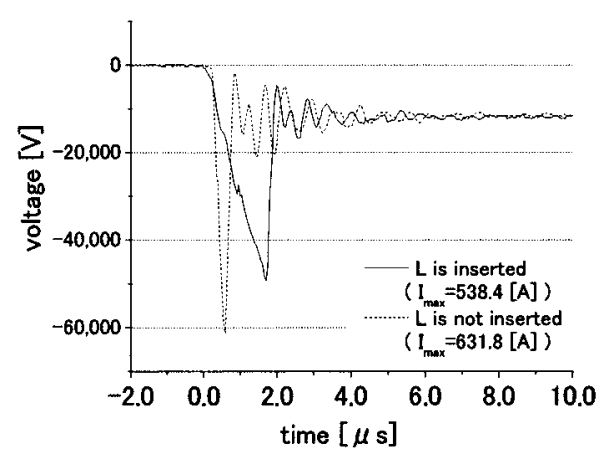

Fig. 8. Difference in waveforms of bushing voltage for cases with and without L (Case1, Device A, grounding resistance $104 \Omega$ )

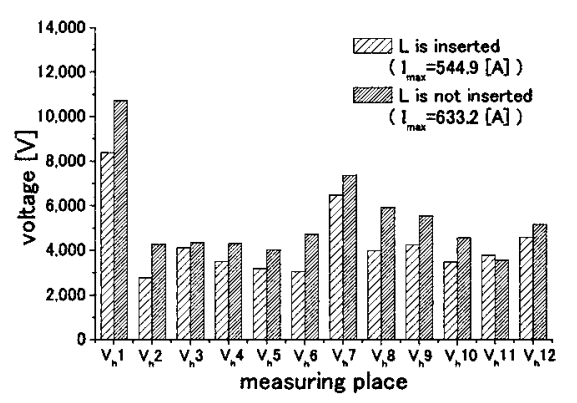

Fig. 9. Voltage distribution of primary windings (Case 2, Device A, grounding resistance $104 \Omega$ )

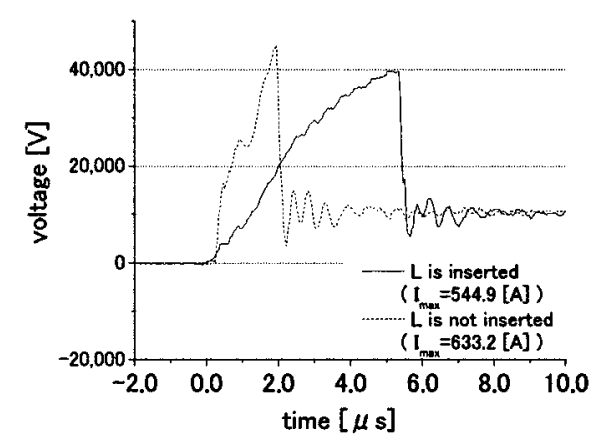

Fig. 10. Difference in waveforms of bushing voltage for cases with and without L (Case 2, Device A, grounding resistance $104 \Omega$ )

L. In case with L, the operating voltage is lower and the operating time is slower than that in case without $\mathrm{L}$.

(2) Case 2 Figure 9 shows the voltage distribution of the primary windings in Case 2. When the surge arrestor operates, the circuit is the same as that of Case1. Therefore, the voltage distribution is similar to Case 1 . Figure 10 shows the difference in waveforms of bushing voltage for cases with and without L. In Case 2, the potential rise of the secondary side of Device A has a slower slope than that in Case 1 because of the inductivity of grounding system. Therefore, compared with Case 1, the operating voltage is lower and the operating time is slower than that in Case 1.

3.3 Measures Against Voltage Reduction In this section, two items are examined, aiming at the reduction of $\mathrm{V}_{\mathrm{h}}$ 1. One is the influence of the operating voltage of the surge arrestors. Another is the influence of the grounding resistance of the surge arrestors.

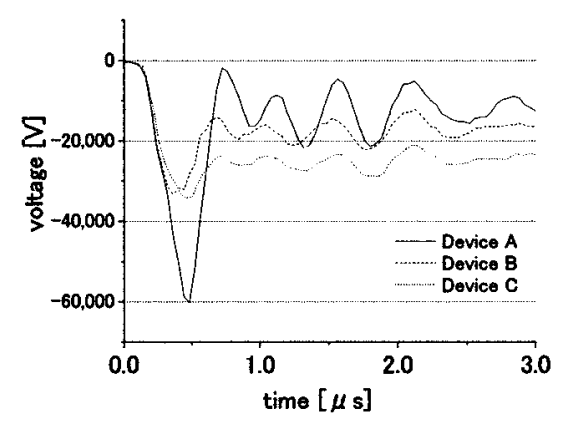

Fig. 11. Comparison of the bushing voltage between Devices A, B and C (Case 1, grounding resistance $46 \Omega$ )

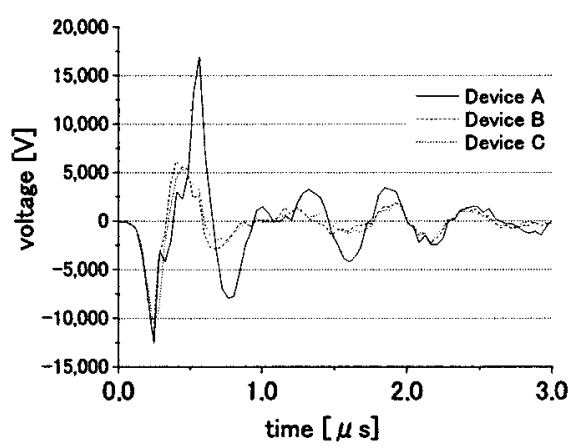

Fig. 12. Comparison of the waveform of $V_{h} 1$ between Devices A, B and C (Case 1, grounding resistance $46 \Omega$ )

(1) Influence of operating voltage of surge arrestor The surge arrestor (Devices A, B, C) is installed in the primary side. Then, the differences in $\mathrm{V}_{\mathrm{h}} 1$ are examined. Figure 11 shows the comparison of the waveforms of bushing voltage (between 1 terminal and enclosure terminal) when each surge arrestor is installed in the primary side.

It is found that the peak value of bushing voltage (between 1 terminal and enclosure terminal) with Device A is the highest of all Devices. The difference in voltage between Device $\mathrm{A}$ and other Devices (B and C) is clear. On the other hand, the difference in voltage between Devices B and C is small except that the rising edge of the voltage waveform of Device $\mathrm{C}$ is slower than that of Device $\mathrm{B}$. The reason for this is that Device $\mathrm{C}$ is a gapless-type arrestor and operating current begins to flow before the voltage reaches its peak value.

Figure 12 shows the comparison of $\mathrm{V}_{\mathrm{h}} 1$ between Devices $A, B$ and $C$. In all cases, the vibration cycle of voltage $V_{h} 1$ is shorter than that of bushing voltage shown in Fig. 11. The square voltage transitions shown in Fig. 12 depend on the lack of sampling number. The voltage vibration is influenced by the resonance of capacitance and the inductance (self and mutual), which exist between each measured terminal. Therefore, the peak values and vibration cycles of voltages $\left(\mathrm{V}_{\mathrm{h}} 1-\mathrm{V}_{\mathrm{h}} 12\right.$, bushing voltage) differ from each other.

As shown in Fig. 12, the first wave of voltage $V_{h} 1$, which has a large peak value, occurs at approximately $0.2 \mu$ s in all cases. Compared with the results shown in Fig. 11, this first wave occurs when a similar voltage transition occurs in each device. Therefore, it is difficult to reduce the peak value of the first wave even with the gapless-type arrestor Device C. When Device A is installed, the voltage continues to rise up from $0.2 \mu$ s to $0.5 \mu$ s and the peak value of the second wave is larger than that of the first wave. 


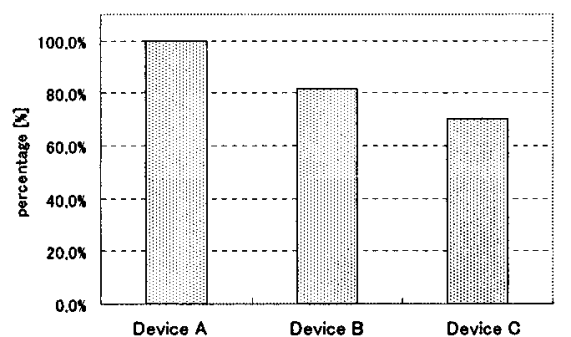

Fig. 13. Effect of surge arrestors (Devices A, B and C) on $\mathrm{V}_{\mathrm{h}} 1$. (Case 1 , grounding resistance $46 \Omega$ )

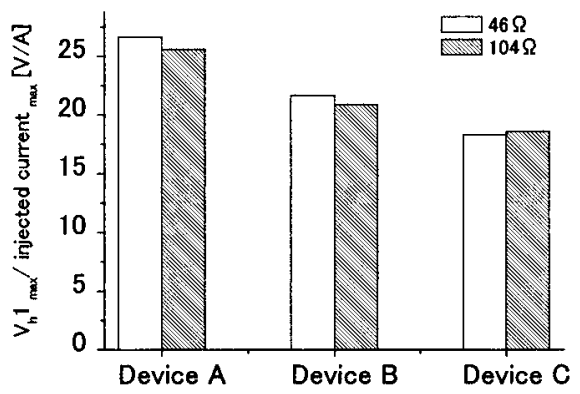

Fig. 14. Effect of grounding resistance on $V_{h} 1$

Figure 13 shows the repression percentage based on the peak value of $\mathrm{V}_{\mathrm{h}} 1$ of Device $A$. The repression percentage of Device B is $82 \%$ and that of Device C is $70 \%$. It is confirmed that a device that operates at a lower voltage is more effective in reducing the peak value of $\mathrm{V}_{\mathrm{h}} 1$.

(2) Influence of grounding resistance of surge arrestors

In this section, the effect of the difference in grounding resistance is examined. The grounding resistance can be switched from $46 \Omega$ to $104 \Omega$. When grounding resistance is low, the impedance on the load side from IG is low. Therefore, the value of the injected current is increased. To remove the variation in the value of the injected current, the peak value of $V_{h} 1$ divided by the peak value of the injected current is adopted as the value of vertical axis. Figure 14 shows the result. From this figure, it is confirmed that $V_{h} 1$ is hardly affected by grounding resistance.

\section{Voltage Distribution of Secondary Windings}

The voltage distribution of the secondary windings is measured under the same conditions of chapter three. There are only two measuring positions of the layer-to-layer of the secondary windings. There are so few measuring positions that the voltage distribution of the secondary windings can hardly be determined. In this chapter, the voltages divided by the four secondary layers are measured. As references, the voltage of the layer-to-layer $\left(\mathrm{V}_{l} \mathrm{t}\right)$ and the voltage of the secondary terminal-to-terminal $\left(2-0,2^{\prime}-0\right)$ are measured.

4.1 Influence of Wavefront Time of Injected Current

(1) Case1 Figure 15 shows the voltage distribution of the secondary windings in Case 1 . It is found that a larger voltage occurs when a steeper wavefront current is injected. $\mathrm{V}_{1} 1$ and $\mathrm{V}_{1} 3$ are larger than $\mathrm{V}_{1} 2$ and $\mathrm{V}_{1} 4$. The reason for this is that the influence of the transfer caused by electrostatic induction as shown in Fig. 16 is more effective for $V_{1} 1$ and $V_{1} 3$.

Next, from the structure of the transformer, $\mathrm{V}_{1} \mathrm{t}$ is determined to be the same value as the difference between $\mathrm{V}_{1} 2$ and $\mathrm{V}_{1} 3$. On the other hand, the voltage between 2 and 0 terminals

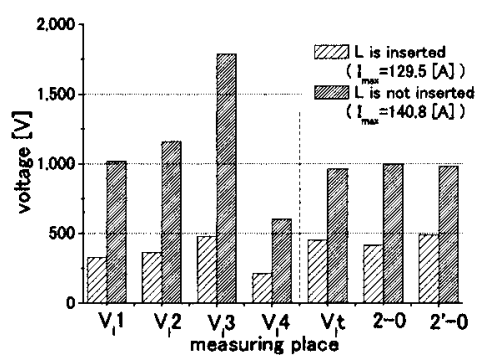

Fig. 15. Voltage distribution of the secondary windings (Case 1 , no surge arrestor, grounding resistance $46 \Omega$ )

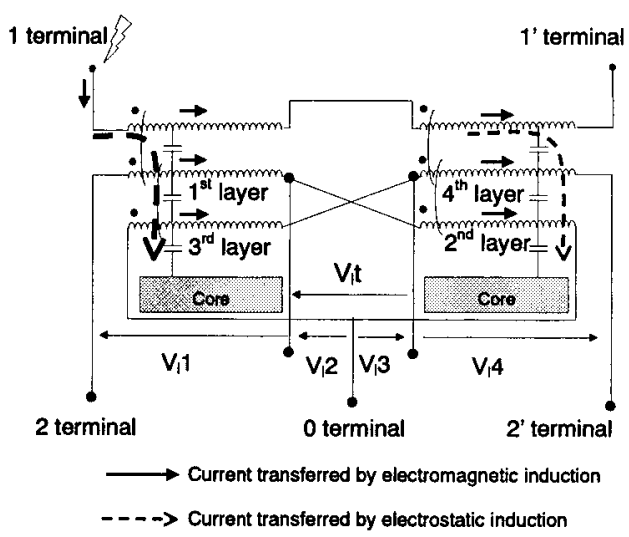

Fig. 16. Direction of the current flowing into the secondary windings (Case 1, no surge arrestor)

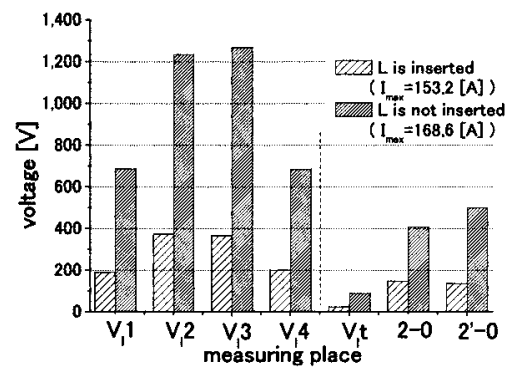

Fig. 17. Voltage distribution of the secondary windings (Case 2, no surge arrestor, grounding resistance $46 \Omega$ )

( $2^{\prime}$ and 0 terminals) is less than the sum of the voltage of $V_{1} 1$ and $V_{1} 3\left(V_{1} 2\right.$ and $\left.V_{1} 4\right)$. The reason for this is as follows. The $1^{\text {st }}$ and $3^{\text {rd }}\left(2^{\text {nd }}\right.$ and $\left.4^{\text {th }}\right)$ layers are adjacent. Therefore, magnetic coupling is effective against the voltage reductions of $\mathrm{V}_{1} 1$ and $\mathrm{V}_{1} 3\left(\mathrm{~V}_{1} 2\right.$ and $\left.\mathrm{V}_{1} 4\right)$. It is confirmed that the interlaced winding of the secondary side is effective for the reduction of the impulse voltage occurring at the secondary windings ${ }^{(4)}$.

(2) Case 2 Figure 17 shows the voltage distribution of the secondary windings in Case 2. Similarly to Case 1, the higher voltage occurs when the steep wavefront current is injected. However, the voltage distribution differs from Case 1. The reason for this is as follows. As shown in Fig. 18, the transfer caused by electrostatic and electromagnetic induction is balanced on the left-hand side and right-hand side of the secondary windings wound on each core. Next, the voltage $\mathrm{V}_{1} \mathrm{t}$ is the difference between $\mathrm{V}_{1} 2$ and $\mathrm{V}_{1} 3$ as mentioned above. In this case, $\mathrm{V}_{1} 2$ has almost the same value as $\mathrm{V}_{1} 3$. Therefore, $\mathrm{V}_{1} \mathrm{t}$ is small.

4.2 Influence of Surge Arrestor Operation

(1) Case1 Figure 19 shows the voltage distribution 


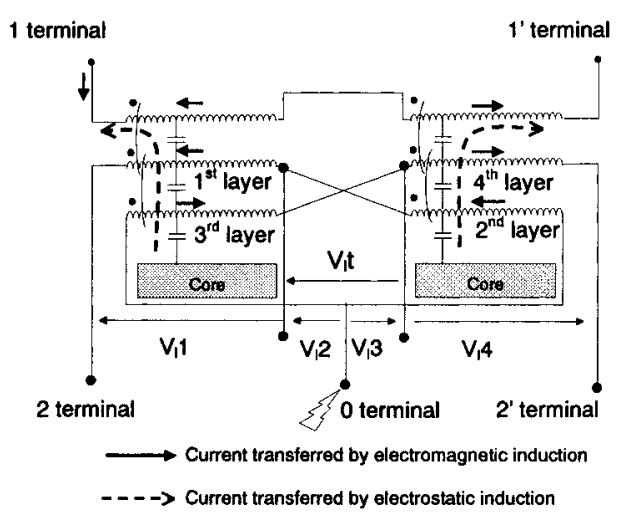

Fig. 18. Direction of the current flowing into the secondary windings (Case 2 , no surge arrestor)

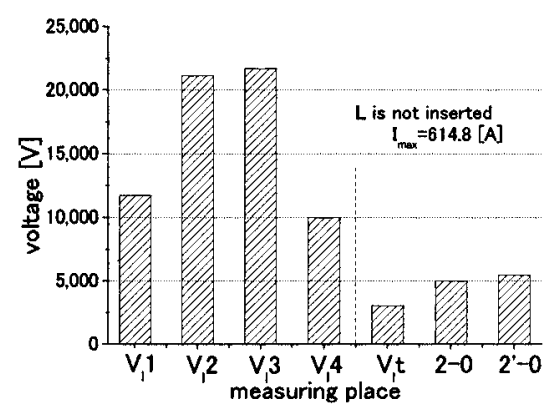

Fig. 19. Voltage distribution of the secondary windings (Case 1, Device A, grounding resistance $104 \Omega$ )

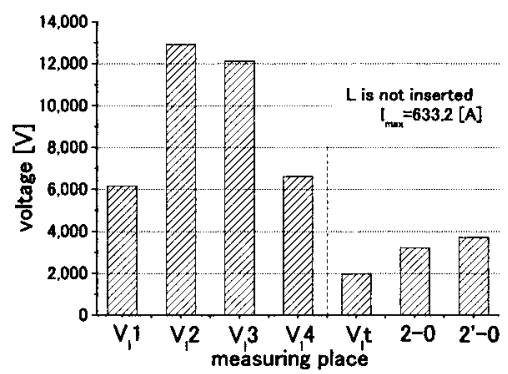

Fig. 20. Voltage distribution of the secondary windings (Case 2, Device A, grounding resistance $104 \Omega$ )

of the secondary windings in Case 1 . When the surge arrestor operates, the operating current flows into the 0 terminal of the secondary side. Therefore, the voltage distribution is similar to Case 2 of the former section 4.1.

(2) Case 2 Figure 20 shows the voltage distribution of the secondary windings in Case 2. Although the circuit is the same as that of Case 1 when the surge arrestor operates, the voltages occurring at each layer are smaller than those in Case 1. The reason for this is that a considerable amount of current flows into the ground before the surge arrestor operates.

4.3 Measures Against Voltage Reduction In this section, the effect of the surge arrestors on the reduction in the voltage of the secondary windings is examined.

(1) Influence of operating voltage of the surge arrestor at the primary side Figure 21 shows the voltage distribution of the secondary windings in Case 1 , when Device A or Device $C$ is installed at the primary side. The peak value of $V_{1} 3$ is the largest among the layers in the secondary windings. Moreover, the transition of $\mathrm{V}_{1} 3$ is shown in Fig. 22. From

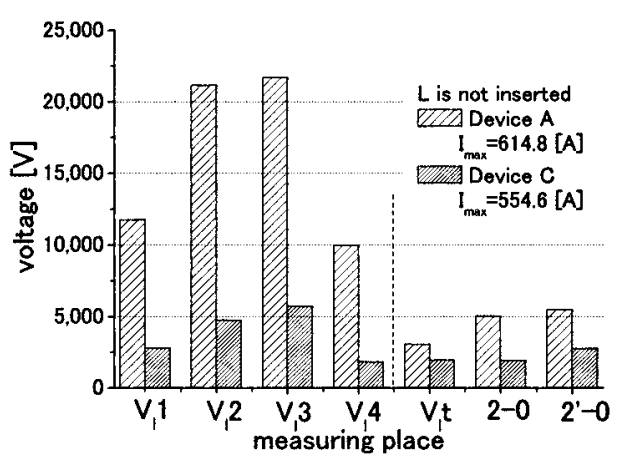

Fig. 21. Voltage distribution of the secondary windings (Case 1, grounding resistance $104 \Omega$ )

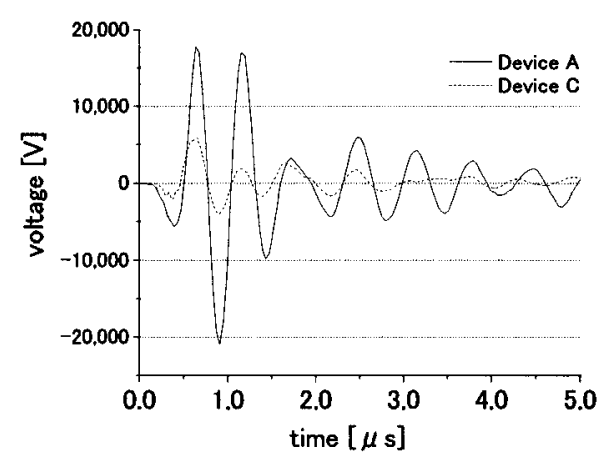

Fig. 22. Comparison of voltage waveform of $\mathrm{V}_{1} 3$ between case using Device A and case using Device C

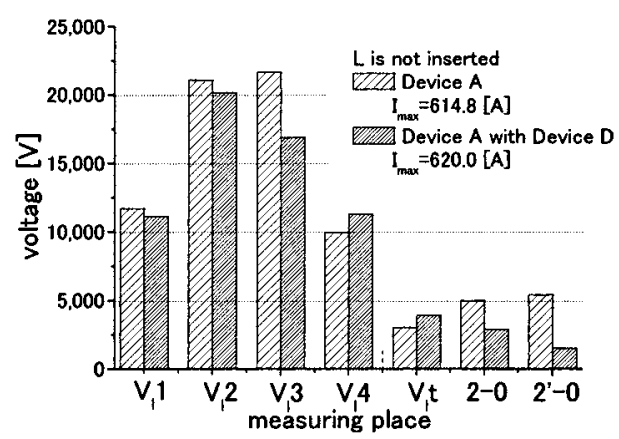

Fig. 23. Voltage distribution of the secondary windings (Case 1, grounding resistance $104 \Omega$ )

both figures, it is confirmed that the voltage occurring at the secondary winding with Device $\mathrm{C}$ is much smaller than that with Device A. The lower operating voltage of the surge arrestor installed in the primary side is effective in reducing the voltage occurring at the secondary windings.

(2) Adding surge arrestors at the secondary side The effect of the low-voltage surge arrestor (Device D) on the voltage reduction of the secondary windings is examined. Under the condition that the Device A is installed in the primary side, low-voltage surge arrestors (Device D) are added at the secondary side. Figure 23 shows the comparison of the voltage distribution of the secondary windings between case using Device A and case using Devices A with D. Figure 24 shows the comparison of voltage waveform of $V_{1} 3$. Figure 25 shows the comparison of voltage waveform of line-to-line (2-0). From these figures, it is found that the low-voltage surge arrestors (Device D) are effective in reducing line-toline voltage. However, they are hardly effective in reducing 


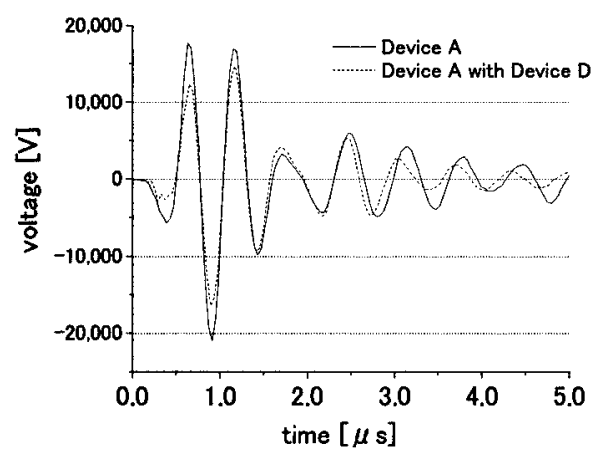

Fig. 24. Comparison of voltage waveform of $V_{1} 3$ between case using Device A and case using Devices A with D

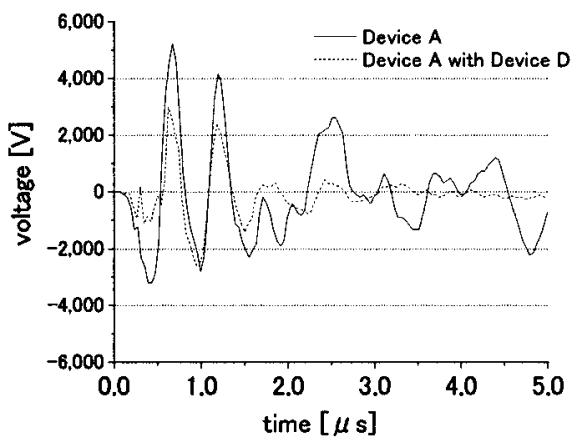

Fig. 25. Comparison of voltage waveform of line-toline (2-0) between case using Device A and case using Devices A with D

the voltage $\mathrm{V}_{1} 3$. The voltage $\mathrm{V}_{1} 3$ is influenced by the arrangement of internal capacitance of transformer. Even if Device $\mathrm{D}$ is installed in the secondary side, it is thought that the influence of internal capacitance on $\mathrm{V}_{1} 3$ is remaining.

Incidentally, as shown in Fig. 25, the peak value of lineto-line voltage reaches about $3 \mathrm{kV}$, though the clamping voltage (table 1) of Device D is $620 \mathrm{~V}$. The reason for this is as follows. The specifications described in Table 1 are applied under the condition of standard lightning surge $(8 / 20 \mu \mathrm{s})$. However, the wavefront time of lightning surge observed in Fig. 25 (approximately $0.4 \mu \mathrm{s}$ ) is much faster than that of standard lightning surge $(8 \mu \mathrm{s})$. Therefore, Device D could not reduce the voltage adequately until around $2 \mu \mathrm{s}$.

\section{Conclusion}

When steep voltage enters a transformer (impulse current is injected into the $\mathrm{R}$ phase of high-voltage wires, and a surge arrestor installed at the primary side operates), the voltage distributions of the primary windings and the secondary windings are measured using a testing transformer. The main conclusions are summarized as follows

(1) Primary windings

(i) Weak point: Large voltage $\left(V_{h} 1\right)$ occurs at the layer nearest the bushing (1 terminal) at the primary side, and the possibility of breakdown at this point is high.

(ii) Measures: The lower the operating voltage of the surge arrestor installed in the primary side, the lower the voltage occurring at the primary windings. There is hardly any effect of grounding resistance on the voltage.
(2) Secondary windings

(i) Weak point: Large voltage $\left(\mathrm{V}_{1} 2\right.$ and $\left.\mathrm{V}_{1} 3\right)$ occurs at the layer closer to the neutral terminal ( 0 terminal), and the possibility of breakdown at this point is high.

(ii) Measures: The lower the operating voltage of the surge arrestor installed in the primary side, the lower the voltage occurring at the secondary windings. Adding the surge arrestor in the secondary side, although effectively reduce line-to-line voltage, does not effectively reduce the voltage of the secondary windings.

(Manuscript received Nov. 1, 2004,

revised Feb. 7, 2005)

\section{References}

( 1 ) Subcommittee for Power Distribution System, Lightning Protection Design Committee: "Guide of Lightning Protection Design for Power Distribution Lines”, CRIEPI Rep., No.T69 (2002) (in Japanese)

( 2 ) T. Nakamura, Y. Morooka, M. Sakae, and A. Asakawa: "Measurement of Potential Distribution in the Primary Windings of the Pole-Type Transformer on Test Distribution Line", Proc. of the Annual Conf. of Power \& Energy Society, 378 (2001) (in Japanese)

( 3 ) M. Ishii, S. Yokoyama, Y. Imai, Y. Hongo, H. Sugimoto, and Y. Morooka: "Lightning Protection of Pole-Mounted Transformer on Japanese MV Lines", Proc. of CIGRE 2004, C4-305 (2004)

( 4 ) C.J. Mcmillen: "Scaled Low-Voltage Side Surge Current Test on a Model Distribution System”, IEEE Trans. Power Delivery, Vol.3, No.2 (1988-4)

Hideki Honda (Member) was born in Niigata, Japan, on August 30,

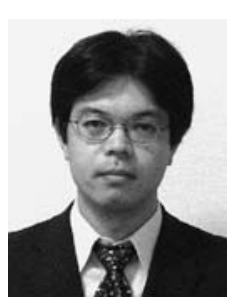
1967. He received the B.S. and M.E. degrees in electrical engineering from Tohoku University, Japan, in 1991 and 2001, respectively. In 1991, he joined Tohoku Electric Power Co., Sendai, Japan, and he had been on loan to Central Reserch Institute of Electric Power Industry, Tokyo, Japan since 2001 to 2004. Since 2004, he has been engaged in the study of distribution systems in the Research \& Development Center.

Akira Asakawa (Member) was born in Hokkai-do, Japan, on April

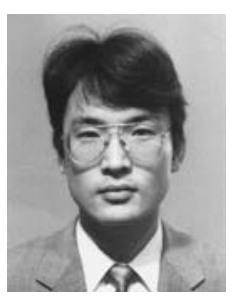
19, 1960. He received the M.E. degree in electrical engeering from Keio University, Japan, in 1985. In the same year he joined Central Reserch Institute of Electric Power Industry, Tokyo, Japan. Since 1985, he has been engaged in the reserch of lightning protection and inslation co-ordination of distribution systems in Electric Power Engineering Research Laboratry.

Shigeru Yokoyama (Member) was born in Miyagi, Japan, on March

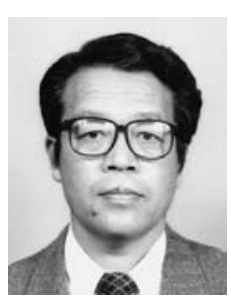
5, 1947. He received the B.S. and Ph.D. degrees from the University of Tokyo, Japan, in 1969 and 1986, respectively. He joined Central Reserch Institute of Electric Power Industry, Tokyo, Japan, in 1969 and since then, he has been engaged in the reserch of lightning protection and inslation co-ordination of distribution and transmission systems. He holds the posts of Exective Reserch Scientist in Electric Power Engineering Research Laboratry of CRIEPI and Professor at Kyushu University concurrently since 2001. He is an IEEE fellow. 